Sādhanā Vol. 40, Part 7, October 2015, pp. 2239-2251. (C) Indian Academy of Sciences

\title{
Investigation of innovative steel runway beam in industrial building
}

\author{
MAHYAR MAALI $^{1}$, ABDULKADIR CÜNEYT AYDIN $^{1, *}$ and \\ MERVE SAĞIROĞLU²
}
${ }^{1}$ Ataturk University, Engineering Faculty, Civil Engineering Department, 25240 Erzurum, Turkey
${ }^{2}$ Erzurum Technical University, Engineering Faculty, Civil Engineering Department, 25200 Erzurum, Turkey
e-mail: acaydin@atauni.edu.tr

MS received 15 October 2014; revised 12 April 2015; accepted 1 June 2015

\begin{abstract}
The design of a runway beam for overhead cranes is of great importance when constructing steel structures, as is the lateral-torsional buckling (LTB) value obtained for I-beam sections. Therefore, engineers must always consider the optimal design of these beams under overhead cranes loads. In this study, runway beams of three overhead crane groups were analyzed for LTB, and a sinusoidal runway beam body was developed. These runway beams with different sinusoidal angles were analyzed by using the finite element method (ABAQUS) and compared to each other and other runway IPE-IPN beam sections; furthermore, all models were compared with the Canadian Institute of Steel Construction standard. As a result, a new method was proposed for developing sinusoidal runway beams for overhead cranes. The sinusoidal runway beam has lower weight than runway IPE-IPN beam sections. Ultimately, a sinusoidal beam body was developed practically with a scale of 1:1.
\end{abstract}

Keywords. Lateral-torsional buckling (LTB); Canadian Institute of Steel Construction; sinusoidal; runway beam; finite element method.

\section{Introduction}

Runway beams are of great importance in overhead crane groups because they carry the crane. Therefore, engineers and designers have focused on the optimal design of high-strength and lowweight runway beams. Each runway is designed to support a specific crane or group of cranes. The weight of the crane bridge and wheel spacing for the specific crane should be obtained from the crane manufacturer (Fisher \& Van De Pas 2002). The crane weight can vary significantly depending on the classification of the crane (Fisher \& Van De Pas 2002). Classes of cranes are defined in

${ }^{*}$ For correspondence 
the Canadian Standards Association (CSA) B167 standard or in specifications of the Crane Manufactures Association of America (CMAA) (CSA 1996; CMAA 2010a-\#70; CMAA 2010b-\#74) based on the frequency of crane use and percentage of lifts at or near the rated capacity, as shown in table 1.

Based on the manufacturer's data, forces are determined to account for impacts and lateral and longitudinal loads. The American Society of Civil Engineers (ASCE 7-1998) addressed crane loads and set minimum standards for these loads. The American Iron and Steel Engineers (AISE, 1996a, b-no.6, no.13) also set minimum requirements for impacts and lateral and longitudinal loads. The AISE requirements are used when the engineer and owner determine that the quality level set by the AISE Guide is appropriate for a given project. Vertical crane loads are termed as wheel loads (AISE 1996a, b). Most codes require a 25\% increase in loads for cab- and radiooperated cranes and a $10 \%$ increase for pendant-operated cranes. Lateral crane loads are oriented perpendicular to the crane runway and are applied at the top of the rails. Lateral loads are caused by the following factors (AISE 1996a, b):

- Acceleration and deceleration of trolley and loads

- Non-vertical lifting

- Unbalanced drive mechanisms

- Oblique or skewed travel of bridge

The ASCE Specification (AISC 1989) and most model building codes set the magnitude of lateral loads at $20 \%$ of the sum of the weights of the trolley and lifted load. The AISE Guide (AISE 1996a, b) varies the magnitude of the lateral load based on the function of the crane. For crane runway stress checks, the AISE equations are based on the 1989 AISC provisions (AISC 1989).

Longitudinal crane forces are caused by either acceleration or deceleration of the bridge crane or the crane impacting a bumper. The tractive forces are limited by the coefficient of friction of the steel wheel on the rails. The force imparted by impact with hydraulic- or spring-type bumpers is a function of the bumper stroke length, crane velocity upon impact with crane stop, and supported weight of end truck. The longitudinal forces should be obtained from the crane

Table 1. CSA and CMAA service classifications.

\begin{tabular}{|c|c|c|}
\hline Class & Near rated capacity & $\overline{\text { Lifts per hour }}$ \\
\hline Standby or infrequent service (A) & $\begin{array}{l}\text { The cranes may handle loads at the rated capacity } \\
\text { for initial installation of equipment and for } \\
\text { infrequent maintenance }\end{array}$ & - \\
\hline Light service (B) & $\begin{array}{l}\text { The cranes handle loads varying from no load to } \\
\text { occasional full-rated loads }\end{array}$ & $2-5$ \\
\hline Moderate service $(\mathrm{C})$ & $\begin{array}{l}\text { The cranes handle loads that average } 50 \% \text { of } \\
\text { the rated capacity }\end{array}$ & $5-10$ \\
\hline Heavy service (D) & $\begin{array}{l}\text { The cranes constantly handle loads approaching } \\
50 \% \text { of the rated capacity during their } \\
\text { working period }\end{array}$ & $10-20$ \\
\hline Severe service $(\mathrm{E})$ & $\begin{array}{l}\text { The cranes handle loads approaching the rated } \\
\text { capacity throughout their life }\end{array}$ & $20+$ \\
\hline Continuous severe service $(\mathrm{F})$ & $\begin{array}{l}\text { The cranes handle loads approaching the rated } \\
\text { capacity continuously under severe service } \\
\text { conditions throughout their life }\end{array}$ & - \\
\hline
\end{tabular}


manufacturer. If this information is not available, the AISE Guide (1996a, b) provides equations that can be used for determining the bumper force (Fisher \& Van De Pas 2002).

A rational method for calculating the factored moment resistance of a laterally unsupported beam, similar to the method proposed by Ellifritt \& Lue (1998), is as follows:

The AISC-LRFD specification uses a straight line transition from the elastic buckling curve at $M_{u}=M_{i}, L=L_{i}$ to $M_{u}=M_{p}, L=L_{p}$. Establish the class of the section in bending and determine whether the limiting strength may be governed by the yield stress or by local flange or web buckling.

for $L \leq L_{p}, M_{r} / \Phi=M_{p}$

for $L_{p}<L \leq L_{i}$.

The unfactored moment resistance for simply supported beams under uniform moment, loaded at the shear center, can be determined by the following equation:

$$
M_{r} / \Phi=M_{p}-\left(M_{p}-M_{i}\right)\left[\left(L-L_{p}\right) /\left(L_{i}-L_{p}\right)\right] \leq M_{p}
$$

for $L>L_{i}, M_{r} / \Phi=M_{u}$.

Galambos's (1998) general formula for $M_{u}$, the critical elastic moment of the unbraced monosymmetric beam, is expressed as follows:

$$
M_{u}=\pi C_{b} / K L\left[\sqrt{E I_{y} G J}\left(B_{1}+\sqrt{1+B_{2}+B_{1}^{2}}\right)\right],
$$

where

$$
\begin{gathered}
B_{1}=\pi B_{x} / 2 K L\left[\sqrt{E I_{y} / G J}\right] \\
B_{2}=\pi^{2} E C_{w} /(K L)^{2} G J
\end{gathered}
$$

$M_{i}=F_{L} S_{x c}$ or $F_{y} S_{x t}$, whichever is less

$$
L_{p}=1.76 r_{y c} \sqrt{\frac{E}{F_{y}}} .
$$

$L_{i}$ cannot be calculated directly and must be solved by a trial-and-error iteration until the unbraced length used in the formula for $M_{u}$ produces a moment $M_{u}=M_{i}$. That length is then $L_{i}$

The symbols used in these calculations are as follows:

$C_{w}=$ warping section constant

$E=$ Young's modulus of elasticity

$F_{y}=$ yield stress of steel

$G=$ shear modulus of elasticity

$I_{y}=$ second moment of area about y-axis

$J=$ torsional section constant

$M_{p}=$ section plastic moment capacity

$M_{r}=$ lateral-torsional buckling (LTB) moment capacity

$C_{b}=$ moment diagram modifier, dependent on moment gradient, usually taken as 1

$F_{L}=F_{y}-F_{r}$

$F_{r}=$ compressive residual stress in the flange $(69 \mathrm{MPa}$ for rolled shapes and $114 \mathrm{MPa}$ for welded shapes)

$K=$ coefficient to account for increased moment resistance of a laterally unsupported beam segment when subject to a moment gradient, usually taken as 1 
$L_{i}=$ limiting laterally unbraced length for inelastic LTB

$L_{p}=$ limiting laterally unbraced length for full plastic bending capacity, uniform moment case

$R_{y c}=$ radius of gyration of compression flange about beam axis of symmetry

$S_{x c}=$ section modulus referred to compression flange

$S_{x t}=$ section modulus referred to tension flange

Lateral-torsional buckling (LTB) is a limit state of structural usefulness where the deformation of a beam changes from predominantly in-plane deflection to a combined lateral deflection and twisting, before failing due to yielding (Mohebkhah \& Chegeni 2012). Few laboratory tests (Cherry 1960; Richter 1998) have been conducted to study the LTB behavior of locally buckled steel beams. Wang et al (1977) used a finite element method in conjunction with the Winter effective width concept to study LTB of locally buckled beams. They found that a considerable amount of post-buckling strength is available for a locally buckled beam; however, this may not be fully utilized because of lateral buckling in the post-local-buckling range for beams with intermediate span-lengths (Wang et al 1977). Bradford \& Hancock (1984) investigated a nonlinear finite strip method as an alternative to the Winter effective width equation of a locally buckled beam with thin flange out stands to investigate the resistance of the beam to LTB. They showed that for simply supported beams, sections with stockier flanges and thin webs are less likely to be affected by buckling interaction even if the Winter effective width calculation indicates that they will be affected (Bradford \& Hancock 1984). Mohri \& Potier-Ferry (2006) investigated a nonlinear model taking into account flexural-torsional couplings; they derived analytical solutions for the lateral buckling of simply supported I-beams under some representative load cases and established a closed form for lateral buckling moments.

This study aims to investigate the effect of the sinus degrees in the web I-beam of runway beams of an overhead crane on the LTB moment capacity. A finite-element model based on the commercial software package ABAQUS (2012) is developed for the nonlinear inelastic analysis of runway beams of an overhead crane. Then, it is used to investigate the applicability of the Canadian Institute of Steel Construction's (MacCrimmen 2004) approach in estimating the moment capacity of locally buckled built-up steel runway beams of an overhead crane with various sinus degrees in the web I-beam of runway beams. Then, an optimum model of the runway beam, called the sinusoidal web beam, was selected and developed with a scale of 1:1.

\section{Model naming and material properties}

We proposed a new design for a runway beam and developed with a scale of 1:1. Therefore, we should choose plates to create the runway sheet beam as follows:

1. In practice, plates are often used during construction of the sheet beam.

2. The selected plate should be capable of easily creating all favorite sinusoidal angles without geometrical defects that change the bearing capacity.

According to the two abovementioned cases, we used 6-mm sheets in the beam web and 12$\mathrm{mm}$ sheets in the beam flange. After selecting the sheets, the runway beam was created by using the finite element software ABAQUS with a sinusoidal body of length $6,160 \mathrm{~mm}$. This length was selected because the distance between the columns at the research site was $6,160 \mathrm{~mm}$. The plan of the research site is shown in figure 1.

In this study, all finite element models were divided into three groups and analyzed. The first group has degree $\alpha$, where $\alpha$ indicated the degree of sinus dehiscence as shown in figure 2 . 


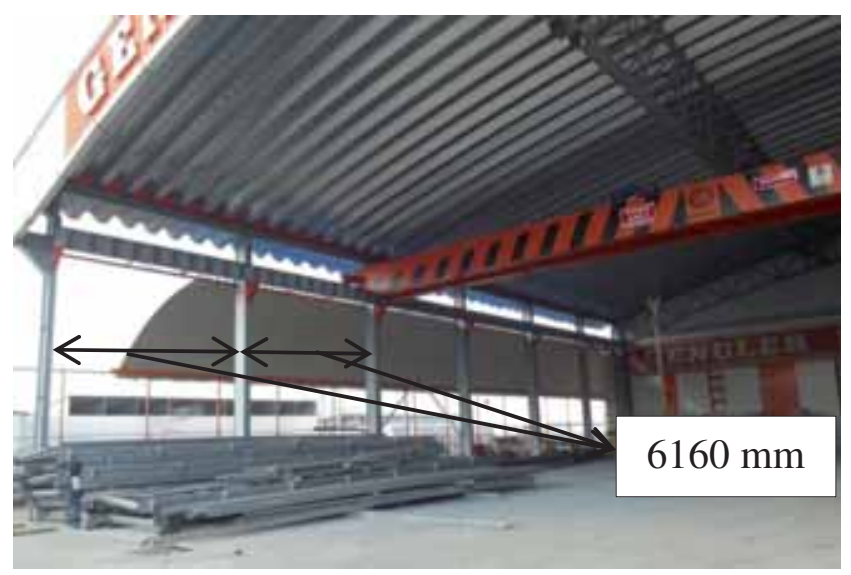

Figure 1. Plan of research site.

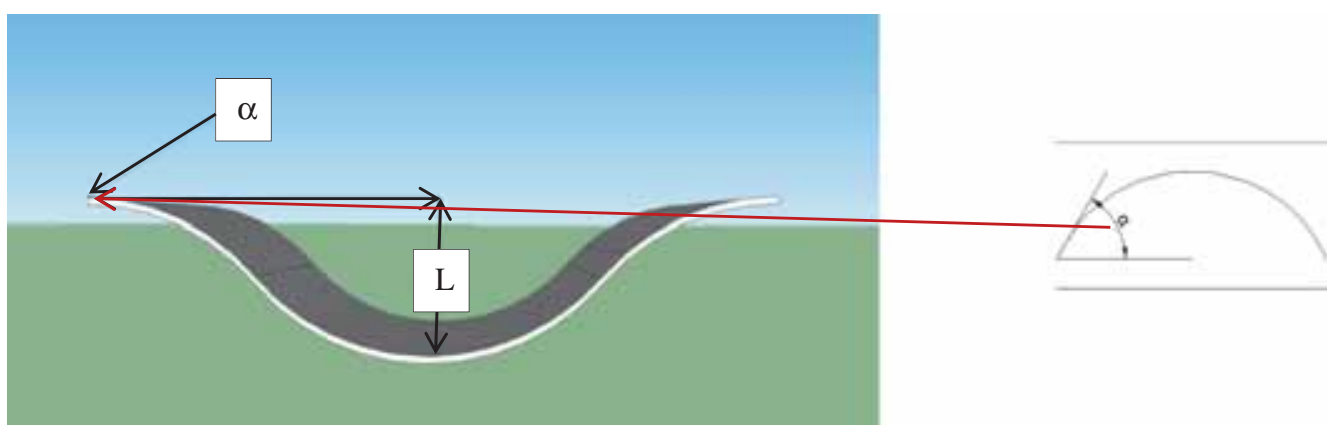

Figure 2. Shape of models.

Table 2. Names of models.

\begin{tabular}{lccccc}
\hline Name of model & $\mathrm{h}(\mathrm{mm})$ & $\mathrm{b}(\mathrm{mm})$ & $\mathrm{t}(\mathrm{mm})$ & $\mathrm{s}(\mathrm{mm})$ & $\mathrm{L}(\mathrm{mm})$ \\
\hline Simple & 500 & 300 & 12 & 6 & - \\
Sinusoidal $10^{\circ}$ & 500 & 300 & 12 & 6 & 28.6 \\
Sinusoidal $20^{\circ}$ & 500 & 300 & 12 & 6 & 57.2 \\
${\text { Sinusoidal } 30^{\circ}}^{\circ}$ & 500 & 300 & 12 & 6 & 85.8 \\
${\text { Sinusoidal } 40^{\circ}}^{\circ}$ & 500 & 300 & 12 & 6 & 114.4 \\
Sinusoidal $45^{\circ}$ & 500 & 300 & 12 & 6 & 128.7 \\
Sinusoidal 50 & 500 & 300 & 12 & 6 & 143 \\
Sinusoidal 60 & 500 & 300 & 12 & 6 & 171.6 \\
Sinusoidal 70 & 500 & 300 & 12 & 6 & 200.2 \\
Sinusoidal 80 & 500 & 300 & 12 & 6 & 228.8 \\
IPN360 & 360 & 143 & 19.5 & 13 & \\
IPN380 & 380 & 149 & 20.5 & 13.7 & \\
IPN400 & 400 & 155 & 21.6 & 14.4 & - \\
IPN450 & 450 & 170 & 24.3 & 16.2 & \\
IPE450 & 450 & 190 & 14.6 & 9.40 & \\
IPE500 & 500 & 200 & 16 & 10.20 & - \\
IPE550 & 550 & 210 & 17.20 & 11.10 & \\
\hline
\end{tabular}




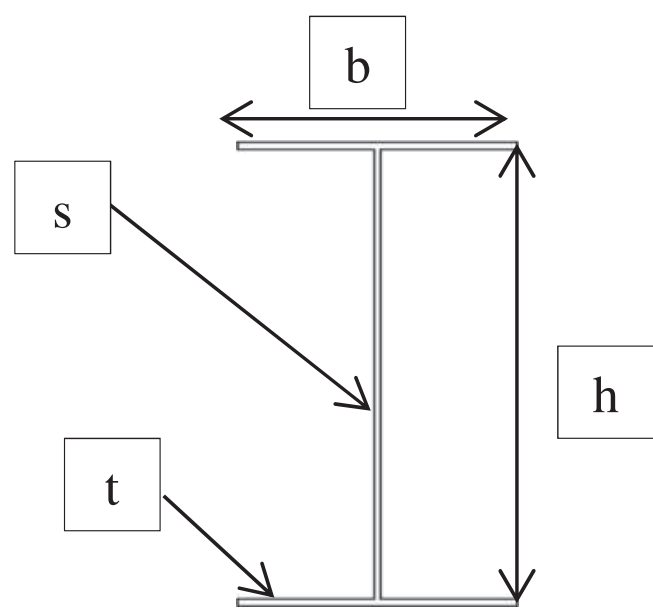

Figure 3. Shape of profiles.

The second and third groups are related to IPN and IPE profiles, respectively. The profile characteristics are shown in table 2 and figure 3.

In all models, the modulus of elasticity value of $210,000 \mathrm{MPa}$, nominal yield stress value of $240 \mathrm{MPa}$, and ultimate yield stress value of $350 \mathrm{MPa}$ are specified. Poisson's ratio was set to 0.3. Residual stresses were not considered, though they may be relevant in this type of analysis.

\section{Nonlinear finite-element model}

To investigate the inelastic LTB capacity behavior of built-up IPE, IPN, and sinus web I-beams of runway beams of an overhead crane, a nonlinear inelastic finite element model is developed based on the specifications and assumptions given in the following sections.

\subsection{Mesh}

The nonlinear computations were performed using the commercial finite element software package ABAQUS (2012). ABAQUS (2012) can be used to consider both geometric and material nonlinearities in a given model. Large displacement effects were accounted for by utilizing the nonlinear geometry option in ABAQUS. A four-node doubly curved shell element with reduced integration S4R (ABAQUS 2012) from the ABAQUS element library was used to model the web and flanges. The S4R element is suitable for complex buckling behavior. It has six degrees of freedom per node and provides accurate solutions to most applications (Mohebkhah \& Chegeni 2012). Flanges were modeled with four elements across the width and seven elements across the web height.

\subsection{Crane runway loads and RIKS analyses}

Simply supported built-up IPE, IPN, and sinusoidal web beams of runway beams with different degrees are chosen under pure bending conditions to evaluate their moment capacity. A RIKS buckling method (ABAQUS 2012) that uses a geometrically nonlinear load-displacement in the 


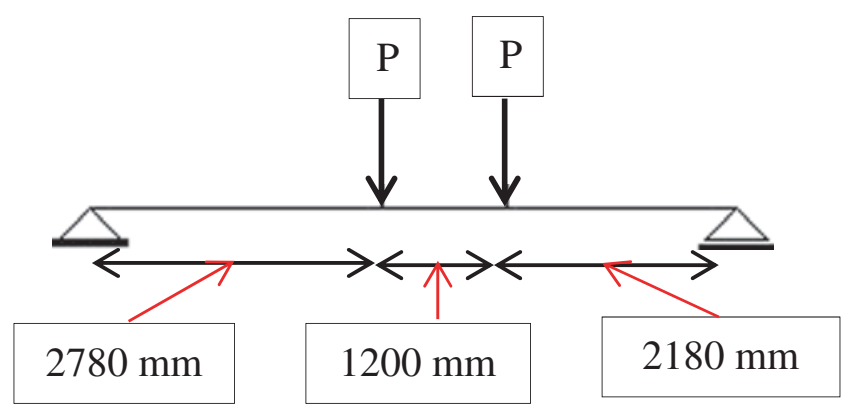

Figure 4. Loading model.

elastic solution procedure is utilized. Geometric imperfections are also accounted for in the analysis. To obtain a suitable imperfection pattern, an eigenvalue analysis is performed to determine the buckled mode shape of the beam when subjected to the applied loads. Such analysis is linear elastic analysis performed with the load applied within the step. A scaling coefficient of 2 $\mathrm{mm}$ is chosen to represent the maximum value of geometric imperfections and then, the eigen shape is added to the original geometry to create a new geometry with an imperfection pattern (Mohebkhah \& Chegeni 2012). The forces acting on runway beams were calculated according to the Canadian Institute of Steel Construction regulations; the lifted load is $78.48 \mathrm{kN}$, trolley load is $10.59 \mathrm{kN}$, crane runway beam span is $6,160 \mathrm{~mm}$, and crane wheel base is $1,200 \mathrm{~mm}$. The loading model is shown in figure 4.

\section{Validation of modeling technique}

In this section, the accuracy of the finite element model of the I-beams is investigated. Toward this end, Mohebkhah \& Chegeni (2012) performed a comparison using the available results of the finite element models on the local buckling of inelastic built-up I-beams under pure bending with tests of Richter's master's thesis (1998). Mohebkhah and Chegeni's model was loaded at the side span ends and subjected to a uniform moment, as shown in figure 5. Sections 27 and 28 of Mohebkhah and Chegeni's model were selected for comparison with the proposed modeling technique. Mohebkhah \& Chegeni (2012) used the yield stress in the flange as $48.6 \mathrm{ksi}$ and the yield stress in the web as $52.0 \mathrm{ksi}$. Young's modulus was set to 29,000 ksi and Poisson's ratio was set to 0.3. Residual stresses were not considered in this validation. Table 3 shows a comparison between the load buckling obtained from Mohebkhah and Chegeni's finite element analysis and the proposed finite element analysis technique; the two show a negligible difference

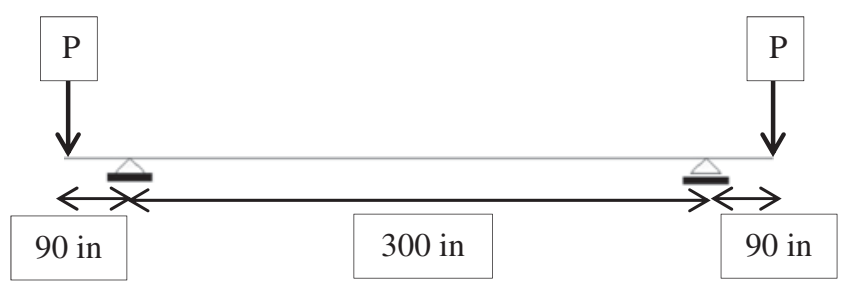

Figure 5. Built-up beam tested by Richter (1998). 
Table 3. Comparison of built-up beam tests results from Mohebkhah and Chegeni's (2012) finite element analysis and the FEM results.

\begin{tabular}{lcccccc}
\hline Model no. & L (in) & H (in) & $\begin{array}{c}\text { P (Richter } \\
\text { test) }(1998)\end{array}$ & $\begin{array}{c}\text { P (M \& C) } \\
(2012)\end{array}$ & P (FEM) & $\begin{array}{c}\text { Difference (\%) P (M \& C) } \\
\text { (2012) and P (FEM) }\end{array}$ \\
\hline 27 & 100 & 24 & 28.2 & 27.45 & 27.31 & 0.51 \\
28 & & 30 & 35.1 & 36.7 & 36.58 & 0.32 \\
\hline
\end{tabular}

M \& C $=$ result of Mohebkhah and Chegeni's finite element analysis (2012).

between $0.51 \%$ and $0.32 \%$. Good agreement is observed between the load buckling obtained by Mohebkhah and Chegeni's and our nonlinear finite element analysis.

\section{Discussion}

After validating the finite element model, a nonlinear analysis was performed considering the effect of the sinus web on the LTB moment capacity of built-up I-beams. All models were analyzed with different web degree of the I-beam section and different IPE and IPN in three groups to study the LTB moment capacity (17 models in total). The FEM moment capacities are compared in table 4 to the moments predicted by the Canadian Institute of Steel Construction's LTB provisions. According to table 4 and figure 6, nonlinear analysis was performed on three groups of models. The maximum displacement, buckling moment capacity of FEM, buckling moment capacity as per the Canadian Institute of Steel Construction, and weight are indicated in this

Table 4. Comparison of the Canadian Institute of Steel Construction and FEM moment capacities of the studied beam sections.

\begin{tabular}{|c|c|c|c|c|c|c|c|c|}
\hline Model name & $\mathrm{L}_{\mathrm{P}}(\mathrm{m})$ & $\mathrm{L}_{\mathrm{i}}(\mathrm{m})$ & $\mathrm{M}_{\mathrm{p}}(\mathrm{kN} \cdot \mathrm{m})$ & $\begin{array}{c}\mathrm{M}_{\mathrm{r}}(\mathrm{kN} . \mathrm{m}) \\
\text { ABAQUS } \\
(2012) \mathrm{M}_{\mathrm{r} 1}\end{array}$ & $\begin{array}{l}\mathrm{M}_{\mathrm{r}}(\mathrm{kN} . \mathrm{m}) \\
{[\mathrm{FEM}] \mathrm{M}_{\mathrm{r} 2}}\end{array}$ & $\mathrm{M}_{\mathrm{r} 1} / \mathrm{M}_{\mathrm{r} 2}$ & $\begin{array}{l}\text { Weight } \\
(\mathrm{kg})\end{array}$ & $\begin{array}{c}\mathrm{U}(\mathrm{m}) \\
{[\mathrm{FEM}]}\end{array}$ \\
\hline Simple & 2.1317 & 4.3537 & 733.80 & 660.36 & 659.94 & 1.000636 & 79.95 & 0.025 \\
\hline Sinusoidal $10^{\circ}$ & & 4.037 & & 659.89 & 660.92 & 0.998442 & 80.238 & 0.072 \\
\hline Sinusoidal $20^{\circ}$ & & 3.958 & & 660.95 & 660.93 & 1.00003 & 80.4905 & 0.083 \\
\hline Sinusoidal $30^{\circ}$ & & 5.877 & & 660.78 & 660.75 & 1.000045 & 81.3316 & 0.064 \\
\hline Sinusoidal $40^{\circ}$ & & 4.026 & & 660.94 & 660.93 & 1.000015 & 82.5932 & 0.045 \\
\hline Sinusoidal $45^{\circ}$ & & 4.030 & & 660.94 & 660.92 & 1.00003 & 83.0137 & 0.081 \\
\hline Sinusoidal $50^{\circ}$ & & 4.195 & & 660.93 & 660.89 & 1.000061 & 83.8548 & 0.067 \\
\hline Sinusoidal $60^{\circ}$ & & 4.212 & & 660.92 & 660.92 & 1 & 85.537 & 0.078 \\
\hline Sinusoidal $70^{\circ}$ & & 4.065 & & 660.95 & 660.91 & 1.000061 & 87.2191 & 0.164 \\
\hline Sinusoidal $80^{\circ}$ & & 4.096 & & 660.94 & 660.93 & 1.000015 & 89.32 & 0.133 \\
\hline IPN360 & 0.9779 & 1.97 & 397.73 & 354.46 & 354.42 & 1.000113 & 76.1 & 0.005 \\
\hline IPN380 & 1.061 & 6.007 & 461.29 & 415.04 & 414.91 & 1.000313 & 84 & 0.007 \\
\hline IPN400 & 1.056 & 6.302 & 535.25 & 481.59 & 481.38 & 1.000436 & 92.4 & 0.004 \\
\hline IPN450 & 1.115 & 6.691 & 746.74 & 671.89 & 671.67 & 1.000328 & 115 & 0.003 \\
\hline IPE450 & 1.28277 & 3.496 & 414.56 & 373.045 & 372.96 & 1.000228 & 77.6 & 0.005 \\
\hline IPE500 & 1.34415 & 6.02 & 657.01 & 591.17 & 591.09 & 1.000135 & 90.7 & 0.004 \\
\hline IPE550 & 1.42633 & 5.444 & 940.35 & 846.08 & 845.94 & 1.000165 & 106 & 0.006 \\
\hline
\end{tabular}

$\mathrm{U}=$ maximum displacement of finite element model. 


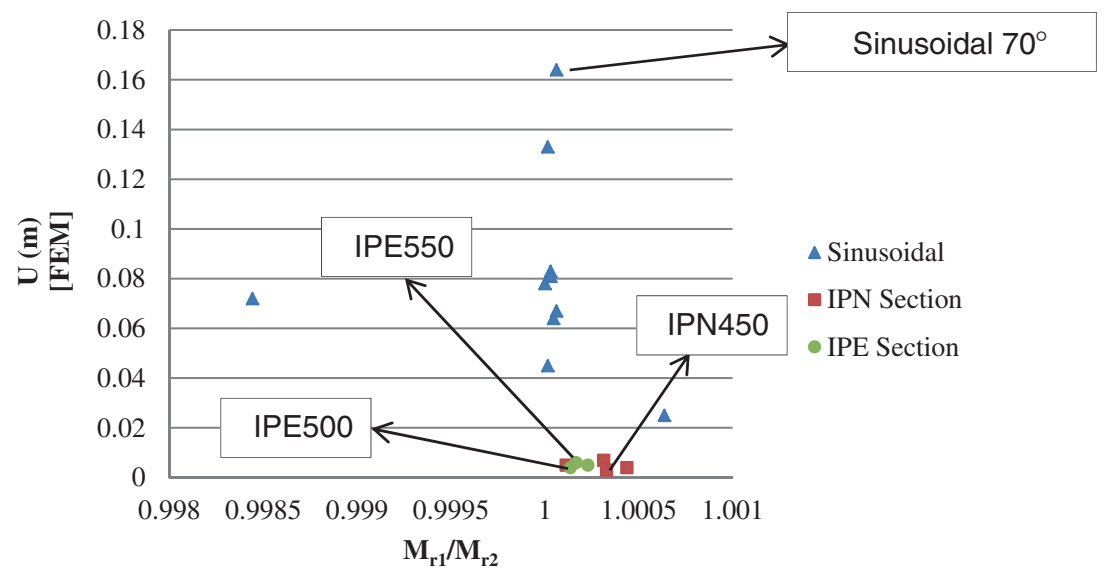

Figure 6. Comparison of Canadian Institute of Steel Construction and FEM moment capacities for all groups.

table. Table 4 and figure 6 show that for the first group, the buckling moment capacity of the Sinusoidal $20^{\circ}$ model and Sinusoidal $70^{\circ}$ model is greater than those of the other models in this group. Furthermore, the maximum displacement is very important, and the Sinusoidal $70^{\circ}$ model shows greater maximum displacement compared to the Sinusoidal $20^{\circ}$ model; therefore, it is better to use the former in this group. In the second group (IPN group), we compare four models with each other. The displacement of the IPN450 model was less than that of the other models. However, the buckling moment capacity of the IPN450 model was greater than that of other models. Therefore, this is an ideal model and will be used for comparison with the other models. However, in the third group (IPE group), according to the buckling moment capacity and maximum displacements, the IPE500 and IPE550 models are ideal models for comparison with other models.

Table 5 shows a comparison of the IPN450, IPE500, and IPE550 models with the Sinusoidal $70^{\circ}$ runway beams. If we compare the IPN450 model with the IPE500 and IPE550 models, the buckling moment capacity of the IPN450 model is lesser than that of the IPE550 model and greater than that of the IPE500 model. Therefore, the IPE550 model is perfect for runway beams under this research load. Furthermore, the displacement of the IPN450 model is less than that of the IPE500 and IPE550 models. Therefore, if we want to choose IPE equal to IPN450, we will choose IPE500 because the buckling moment capacity of IPN450 is nearly equal to that of IPE500. Furthermore, the result of FEM models agrees with that of the Canadian Institute of Steel Construction, with less than $1 \%$ difference between the two.

Table 5 shows a comparison of the weight of the runway beams of the IPN450, IPE500,

Table 5. Comparison of IPN450, IPE500, and IPE550 models with Sinusoidal $70^{\circ}$ runway beams.

\begin{tabular}{lccc}
\hline & $\begin{array}{c}\text { Percent } \mathrm{M}_{\mathrm{r} 1} \text { (MacCrimmen 2004) } \\
\text { models to Mr1 (MacCrimmen } \\
\text { 2004) Sinusoidal 70 }\end{array}$ & $\begin{array}{c}\text { Percent } \mathrm{M}_{\mathrm{r} 2}[\mathrm{FEM}] \text { models to } \\
\mathrm{M}_{\mathrm{r} 2} \text { [FEM] Sinusoidal 70 }\end{array}$ & $\begin{array}{c}\text { Percent weight models to } \\
\text { weight Sinusoidal 70 }\end{array}$ \\
\hline IPN450 & 1.6 & 1.6 & 24.16 \\
IPE500 & -11.80 & -11.81 & 3.837 \\
IPE550 & 21.88 & 21.87 & 17.72 \\
\hline
\end{tabular}




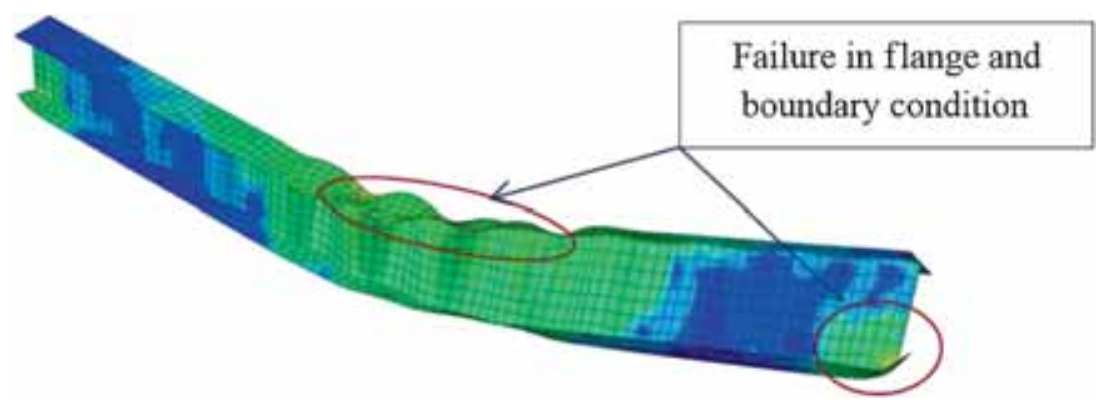

Figure 7. FEM failure model for Sinusoidal $20^{\circ}$.

and IPE550 models with the Sinusoidal $70^{\circ}$ runway beams. The Sinusoidal $70^{\circ}$ beam weighs $24.16 \%, 3.8 \%$, and $17.72 \%$ lesser than the IPN450, IPE500, and IPE550 models, respectively. However, its maximum displacement is 54.66, 41, and 27.33 times that of the IPN450, IPE500, and IPE550 models, respectively. This result indicates that a $70^{\circ}$ runway beam shows a good reaction to loads and displacement.

Furthermore, all failure modes observed in the FEM models show a failure flange in the top flange and in the boundary condition and axial displacement, as shown for the Sinusoidal $20^{\circ}$ model failure in figure 7.

\section{Developing Sinusoidal $70^{\circ}$ model}

Because the web of the sinusoidal beam has 6-mm thickness, first, sheets with dimensions of $1,000 \times 2,000 \mathrm{~mm}$ were prepared. Then, we divided these sheets into two parts using a cutting device. Next, we prepared the cylindrical device shown in figure 8. This device works with three cylinders. To run a $70^{\circ}$ angle, the upper cylinder and two lower cylinders were made with diameters of $269.1 \mathrm{~mm}$ and $238.85 \mathrm{~mm}$, respectively. After making the cylinders, the sheets were made sinusoidal in shape inside this device. These sinusoidal sheets are shown in figure 9. To realize all plan lengths, because the sheet length was $2,000 \mathrm{~mm}$, sheets were welded to each other

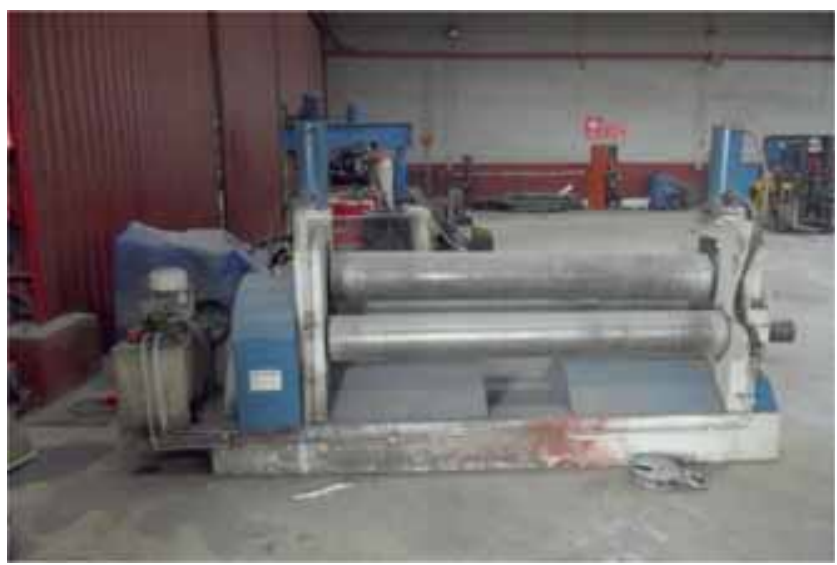

Figure 8. Machine of sinus model. 


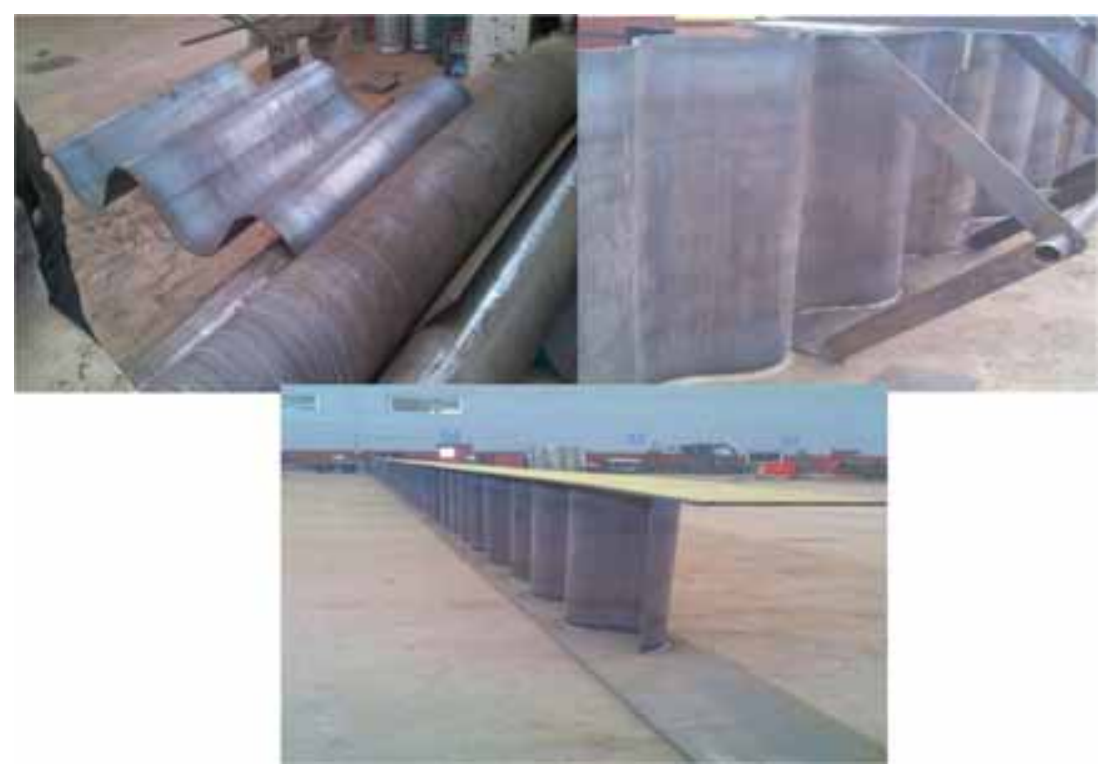

Figure 9. Sinusoidal sheets.

using arc welding with a continuous $45^{\circ}$-fillet weld. The fillet welds were made by the Gençler Metal Company in the down-hand position. The procedure involved manual metal arc welding using a consumable electrode. Three main zones can be identified after the welding process: weld metal (WM), heat-affected zone (HAZ), and base metal (BM), which is the part of the parent plate that is not influenced by the heat input. The HAZ is the portion of the plate on either side of the weld that is affected by heat, owing to which the metal suffers thermal disturbances and

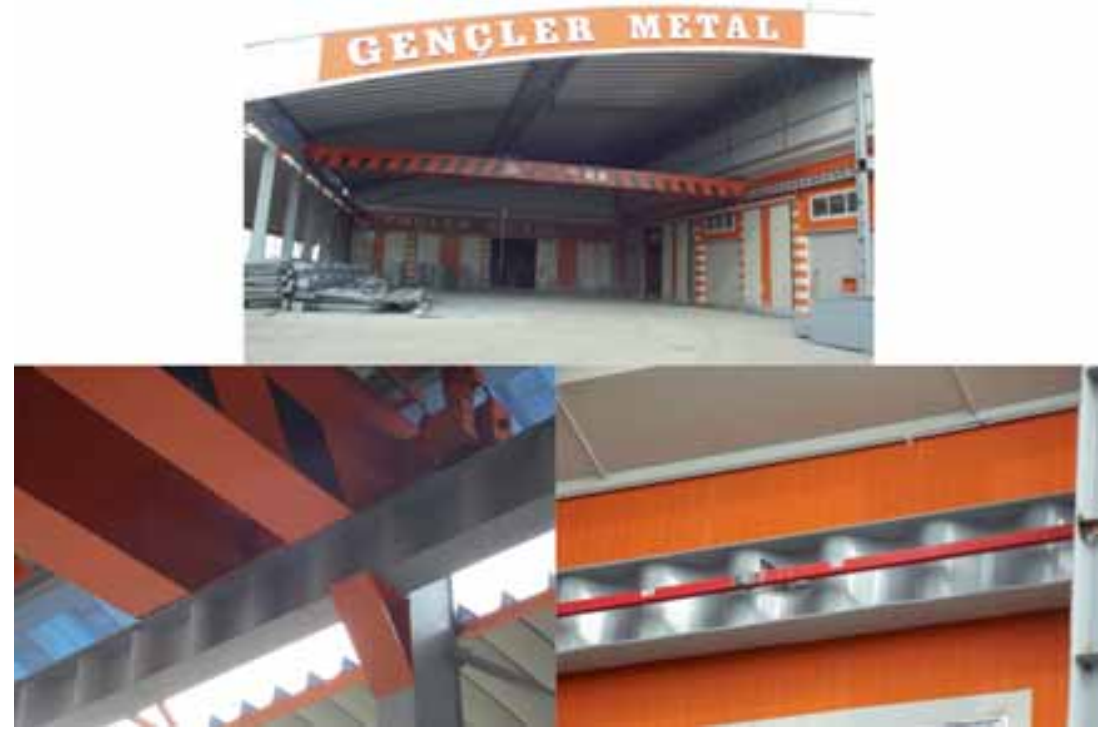

Figure 10. Shape of Sinusoidal $70^{\circ}$ model after completion. 
structural modifications that may include recrystallization, refining, and grain growth. The hot WM causes the plate to bend up owing to shrinkage during cooling, and therefore, considerable force is exerted toward this end. Residual stresses can then be expected in the HAZ. Obviously, this will influence the overall behavior of the connection. The composition of the WM deposited with the electrode compared to that of the BM is of great importance, because this will naturally alter the properties of the steel at and near the weld toe. For each steel quality, there are often a large number of electrode types to choose from (Rodrigues et al 2004; Davies 1992; Girão Coelho et al 2004). After making sinusoidal sheets, wing sheets of 12-mm thickness and 300$\mathrm{mm}$ width were made, and these sheets were cut using the cutting device. Then, sheets wing were carefully welded to each other by arc welding. After welding the wings, they were connected to the web of sinuses by welding. Because of the sinusoidal shape of the web, its vibration was also sinusoidal. The sinusoidal sheets are shown in figure 9 . These sheets were easy to weld, and as a result, the precision of the operation was increased. Figure 10 shows the shape of the Sinusoidal $70^{\circ}$ model after completion.

\section{Conclusion}

In current study, we investigated the LTB of 17 runway beam models by using the finite element method (ABAQUS software) in three groups. As a result, we developed one model with a scale of $1: 1$. The following results were obtained in this study.

1. In the Sinusoidal group, the buckling moment capacity of the Sinusoidal $20^{\circ}$ model and Sinusoidal $70^{\circ}$ model was greater than that of the other models.

2. The maximum displacement is also very important, and the Sinusoidal $70^{\circ}$ model showed greater maximum displacement than the Sinusoidal $20^{\circ}$ model. Therefore, if we use a runway beam according to the sinusoidal model, we could use the Sinusoidal $70^{\circ}$ model.

3. The results of FEM models agree with those of the Canadian Institute of Steel Construction, with less than $1 \%$ difference between the two.

4. The Sinusoidal $70^{\circ}$ beam has $24.16 \%, 3.8 \%$, and $17.72 \%$ lower weight than the IPN450, IPE500, and IPE550 models, respectively.

5. The maximum displacement of the Sinusoidal $70^{\circ}$ beam is $54.66,41$, and 27.33 times that of the IPN450, IPE500, and IPE550 models, respectively.

6. A $70^{\circ}$ runway beam shows good reactions to loads and displacement.

\section{Acknowledgements}

I would like to express my appreciation to Gençler Metal Company and the management of Mr. Zafer GENÇ and Mr. Adem GENÇ, who trusted us, funded our study, and provided their facilities for use as the research site. Furthermore, we would like to express our special appreciation and thanks to the staff of these companies for their cooperation.

\section{References}

ABAQUS 2012 Theory and user's manual, Version 6.12-1

American Society of Civil Engineers (ASCE) 1998 Minimum design loads for buildings and other structures, ASCE7-98, New York, New York

American Iron and Steel Engineers (AISE) 1996a Technical report no. 6, Specification for electric overhead traveling cranes for steel mill service 
American Iron and Steel Engineers (AISE) 1996b Guide for the design and construction of mill buildings, Pittsburgh, Pennsylvania, Technical report no. 13

American Institute of Steel Construction Inc. (AISC) 1989 Specification for structural steel buildings, allowable stress design and plastic design, Chicago, Illinois

Bradford M A and Hancock G J 1984 Elastic interaction of local and global buckling in beams. Thin-Walled Struct. 2: 1-25

CMAA 2010a Specifications for top running bridge and gantry type multiple girder electric overhead travelling cranes, Crane Manufactures Association of America, affiliate of Material Handling Industry, Specification\#70, Revised. Charlotte, North Carolina

CMAA 2010b Specifications for top running bridge and under running single girder electric overhead travelling cranes utilizing under running trolley hoist. Crane Manufactures Association of America, affiliate of Material Handling Industry, Specification\#74, Revised. Charlotte, North Carolina

Cherry S 1960 The stability of beams with buckled compression flanges. Eng. Struct. 38(9): 277-285

CSA 1996 Safety standard for maintenance and inspection of overhead cranes, gantry cranes, monorails, hoists, and trolleys, Canadian Standards Association standard B167-96, Etobicoke, Canada

Davies A C 1992 The science and practice of welding - welding science and technology, vol. I, Cambridge, Cambridge University Press

Ellifritt D S and Lue D M 1998 American Institute of Steel Construction, Engineering Journal, Second Quarter, Chicago, Illinois

Fisher J M and Van De Pas J P 2002 New fatigue provisions for the design of crane runway girders. Eng. J. Second Quarter, 65

Galambos T V 1998 Guide to stability design criteria for metal structures, Fifth Edition, John Wiley and Sons, Inc., New York, New York

Girão Coelho Ana M, Bijlaard Frans S K, Nol Gresnigt and Luís Simões da Silva 2004 Experimental assessment of the behaviour of bolted T-stub connections made up of welded plates. J. Construct. Steel Res. 60: 269-311

MacCrimmen R A 2004 Guide for the design of crane-supporting steel structures, First Editing, Acres International Limited

Mohebkhah A and Chegeni B 2012 Local-global interactive buckling of built-up I-beam sections. ThinWalled Struct. 56: 33-37

Mohri F and Potier-Ferry M 2006 Effects of load height application and pre-buckling deflections on lateral buckling of thin-walled beams. Steel Composite Struct. 6: 401-415

Richter J F 1998 Flexural capacity of slender web plate girders, MS Thesis, Austin, Texas, University of Texas

Rodrigues D M, Menezes L F, Loureiro A and Fernandes J V 2004 Numerical study of the plastic behavior in tension of welds in high strength steels. Int. J. Plasticity 20: 1-18

Wang S T, Yost M I and Tien Y L 1977 Lateral buckling of locally buckled beams using finite element techniques. Comput. Struct. 7(7): 469-475 